\title{
Ángel González
}

«Lo ausente brilla por su propia oscuridad», escribió en cierta ocasión Ángel González; y al recordarle ahora no puedo por más que citarlo así, como se dan cita los amigos, en esa particular experiencia de la ausencia que él mismo describió. «Lo ausente brilla por su propia oscuridad», decía:

Creo recordarlo desde que oí ese neologismo en boca de mi madre. «Por los ausentes», decía ella al añadir una última oración al rezo nocturno del rosario. Y yo, que durante ese rezo soporífero me las había arreglado para dormirme disimuladamente en cualquier postura, solía despertarme al escuchar esta invocación de los ausentes que tanta gracia nos hacía a todos, pues mi madre no hablaba tan finolis, y veía entonces, o tal vez solo entreveía con mis ojos adormilados por la cantinela del rosario, las brillantes y queridas caritas de esos ausentes que se empeñaban en no estar donde les correspondía, fuera de su casa o de su patria, y poco importaba cuán lejos o por qué motivo, casi siempre oscuros para mí, cuando no tontísimos. Y creo recordar también que al mismo tiempo esa luz que brillaba en las caras de los ausentes se me aparecía a mí claramente distinta de la luz mucho menos amable y reconfortante, llameante y tremenda convocaba con otro latinajo: los difuntos... Ni qué decir tiene que todas mis simpatías iban entonces hacia los ausentes, y que solo más tarde empecé a compadecerme de los difuntos y a ver incluso sus propias queridas caritas brillantes, como ahora precisamente la de mi madre, muerta mientras yo me encontraba en una casa muy distante de aquella en que rezábamos el rosario noche tras noche, sin que yo pudiera entender muy bien que probablemente fuera su cantinela lo que nos traía el brillo de los ausentes ${ }^{1}$.

También la escritura de Ángel González está llena de estos ausentes cuyo brillo nos coge como de improviso por estar precisamente ellos ahí donde no se los espera; se debe a deslizamientos, movimientos como los de ese dragón que se nos insinúa en un leve destello en el cuadro que Manet tituló Rosas y un tulipán en un vaso, y que Ángel
González acertó a ver, no ya como decoración en un florero, sino moviéndose dentro del agua, deprisa, con un «brillo escurridizo»². Dragones como ése veía Ángel González allá donde el arte se torna representación de «las inagotables energías del mundo", como decía a propósito de la pintura de Juan Navarro Baldeweg, allá donde «la gravedad deja de ser la dura lex que mantiene separadas la luz y la materia, o lo de arriba y lo de abajo, para franquearnos el camino que lleva a esa región flotante donde nuestros pensamientos tienen los pies ligeros»³. Desde luego que él los tenía; en cierta ocasión comenté con alguien esa cualidad deslizante y llena de giros que encuentro en la escritura de Ángel González, y cuál fue mi sorpresa al escuchar que el profesor que tanto nos deslumbraba en sus clases había sido un experto patinador. Ni que decir tiene que aquello me pareció toda una revelación, más aún cuando esa misma era la sensación de jovialidad revoltosa que primero me asombró en sus textos y más tarde, de igual manera, en sus conversaciones.

Durante mucho tiempo cosechó fama de ágrafo, y con razón ha recordado su amigo Miguel Zugaza que esa fama solo sería conjurada con la publicación de El Resto. Una historia invisible del arte contemporáneo, publicado en 2000 y que al año siguiente le valió el Premio Nacional de Ensayo. Sin embargo, a pesar de tal fama, bastaba con hablar con él para barruntar una estrechísima relación con la escritura. Había sido uno de los críticos de arte más destacados desde finales de los setenta, y lo cierto es que a lo largo de la siguiente década su actividad resulta sorprendente; no solo por lo que escribió en Cambio 16 o en El País cuando dirigía sus páginas de arte, sino también por la organización en los años ochenta de los cursos del Círculo de Bellas Artes, donde presentó a Javier Echeverría o a los italianos Massimo Cacciari y Francesco Dal Co. Lo que más sonó entonces, sin embargo, fueron las exposiciones organizadas con Francisco Calvo Serraller en la Galería Multitud, y sobre todo los comisariados junto a Juan Manuel Bonet y Quico Rivas. Desde luego que cuando uno relee los textos que escribió para aquellas muestras apenas lo reconoce, y de 
hecho, a pesar de lo sonadas que fueron, a pesar incluso de que en aquella época corriera el viento tan de su parte, no creo que considerara aquello sino como peccata minuta. Lo que a Ángel González más le importaba no me parece que tuviera que ver con las inauguraciones, por mucho que disfrutara contando travesuras de la época en que se hablaba del «poderoso trío». Y hablando de poder, buena prueba de lo que digo es que al preguntarle Quico Rivas años más tarde por qué creía que habían perdido ellos el que tenían en los años setenta, la respuesta que le dio Ángel González nos da una idea de a donde apuntaba él: «¿Quieres saberlo Quico?, es muy sencillo, porque nosotros aspirábamos a muchísimo más». «Le contesté lo obvio -le explicaría más tarde a José Díaz Cuyás-, que no aspirábamos a ser críticos de arte poderosos, sino a ser algo más. Lo que estaba diciendo es sencillamente que tanto él como yo aspirábamos a ser escritores" ${ }^{4}$.

Durante mucho tiempo conversé con Ángel González sobre este asunto de la escritura; admiraba al Machado del Juan de Mairena, a Bergamín, a Rafael Sánchez Ferlosio, a Jorge Luis Borges, a Bioy Casares; decía que le hubiera gustado escribir La historia del arte en Italia como lo había hecho Stendhal, y aún recuerdo cómo me explicaba que hay libros que libran del dolor - «el dolor del mundo", me decía- refiriéndose a Paul Léautaud. No parecía demasiado cómodo con la pregunta sobre cómo escribir de arte, pero cuando se animaba a contestar recordaba lo que Juan José Lahuerta le había dicho, que se trataba de comenzar poniendo una palabra acabar poniendo otra. No cabe duda de que la escritura le unía estrechamente a Lahuerta, quien al hablar de este asunto reconocía compartirlo de lleno con Ángel González, «porque él también tiene esta misma sensación: es el escribir mismo el que te va dando ideas. A medida que vas escribiendo y vas viendo, las cosas que escribes se van poniendo en relación con las que estás mirando...»5. Esas relaciones le fascinaban e incluso le daban la pauta para su particular reflexión sobre el arte. Agustín García Calvo le había enseñado cuánto tiene que ver el arte con las articulaciones, y en cierto modo Ángel González no dejó de poner eso en juego en sus textos.

La inquina que mostró hacia las «ideas» - «estropean la pintura», declaraba ${ }^{6}$ - escondía toda una reflexión materialista sobre arte, que a su vez marcaba su particular política de los cuerpos. Era un lector entusiasta de Nietzsche, y aun parecía como si hubiese mantenido una larga conversación con Ernst Jünger o Walter Benjamin de quien se trajo bajo el brazo, tras realizar una estancia en Frankfurt, los textos que Jesús Aguirre publicaría poco después con el título de Haschisch. Siempre tuve la sensación de que Ángel González aún podía discutir con los muertos, a los que devolvía, por así decirlo, la dignidad de la palabra viva; solo así podía alumbrar hipótesis como la que le permitía leer el Passagenwerk de Benjamin como una guía nocturna de París, una Baëdecker de la noche. Como Benjamin, estaba convencido de que «lo eterno es más bien un volante en un vestido que una idea» ${ }^{7}$.

En este sentido comprendió perfectamente lo que el crítico alemán trataba de explicar cuando decía que la dicha de la productividad es comparable a la que Teseo debió de sentir al ir devanando el hilo de Ariadna en el laberinto, como si la productividad misma solo pudiera darse mientras el enigma permanece intacto. Así me parece que hilaba Ángel González las palabras, con el mismo deleite con que hablaba sobre manjares insospechados, puesto que el gusto, en fin, es el gusto. Este ágrafo impenitente, como lo han llamado, estuvo a fin de cuentas cercano a la escritura como de hecho lo estuvo de una poeta, María Vela Zanetti, a la que admiraba y con quien compartió gran parte de su vida.

Cuando en sus clases animaba a observar el vuelo de los vencejos al caer la noche, con sus círculos imprevisiblemente dibujados, desapareciendo a su vez, pues «la noche -decía- es cuando no hay ya círculos en el cielo", nos traía sin que nosotros lo supiéramos reminiscencias de ese lugar abierto por el incesante entrecruzarse de las sensaciones que lo atraviesan. Por ahí comenzaba a enseñar él lo que aún se puede mostrar del arte: por donde «las cosas se esconden para preservar su invisibilidad», por donde lo invisible no es ni mucho menos intangible, sino una suerte de resistencia a su completa desaparición, lo que deja un rastro más que un recuerdo, diría él, «aunque recuerdo ciertamente en el sentido en que decimos que este libro o ese reloj son recuerdos de alguien que ya no está con nosotros»?.

Ángel González ya no lo está; murió el 21 de diciembre de 2014, el día más corto del año, como dice su amigo Javier Arnaldo, "con los rayos del sol haciendo por colarse en su cuarto ${ }^{10}$. Es curioso que Ángel González dijera que «a lo que más se parece el arte es al sol de invierno»; tal vez porque esa luz ha de ser también esa amable y reconfortante 
que él atribuía a los ausentes. De ellos está llena su escritura, desde luego, pero precisamente por ser la ausencia ese resto que se resiste a desaparecer, resto compartido, los restos que en las sobremesas con los amigos llaman irresistiblemente a las manos, los que nos quedan y aún nos unen, pues de algún modo es esto lo que Ángel González nos dijo tantas veces y de tantas maneras:

La virtud por excelencia del arte: su «comensalidad»; esto es, su capacidad de congregar a los hombres y hacerlos partíci- pes de la gozosa sensación de estar en este mundo, como en una de esas sobremesas que entran indolente y voluptuosamente en la noche, mientras los perros guardan la casa de los gatos que la rondan y el orden cambiante de la mesa se refleja en lo alto del cielo con sus constelaciones que giran inadvertidamente, y sus regueros y salpicaduras como los de un mantel sobre el que los dioses celebran su festín ${ }^{11}$.

Daniel Lesmes Universidad Complutense de Madrid

Notas

1 GONZÁLEZ GARCÍA, Ángel, «Casitas», Pintar sin tener idea y otros ensayos sobre arte, Madrid, Lampreave y Millán, 2007, pp. 241-242.

2 GONZÁLEZ GARCÍA, «La pintura se complica», Pintar sin tener idea..., p. 129.

3 GONZÁLEZ GARCÍA, «Todo lo verdadero es invisible», El resto. Una historia invisible del arte contemporáneo, edición de Miguel Ángel García, Madrid, Museo de Bellas Artes de Bilbao, Museo Nacional Centro de Arte Reina Sofía, 2000, p. 441.

4 DÍAZ CUYÁS, José, «Entrevista a Ángel González García, Madrid, julio de 2014», Desacuerdos, 8, p. 231.

5 DÍAZ CUYÁS, José, «Entrevista a Juan José Lahuerta, Barcelona, 17 de septiembre de 2013», Desacuerdos, 8, p. 231.

6 JARQUE, Fietta, «Las ideas estropean la pintura», El País, 5 de abril de 2008.

7 BENJAMIN, Walter, Libro de los pasajes [B 3, 7], traducción de Luis Fernández Castañeda, Isidro Herrera y Fernando Guerrero, Madrid, Akal, p. 97.

8 GONZÁLEZ GARCÍA, «De pura sombra lleno», El resto..., p. 416.

9 GONZÁLEZ GARCÍA, «J. K. va in paradiso", El resto..., p. 429.

10 ARNALDO, Javier, «El arte, un lugar de paso. Recordando a Ángel González García», Cuadernos hispanoamericanos, n. 779, 2015 , p. 118.

11 GONZÁLEZ GARCÍA, «La siesta de las cosas», Pintar sin tener idea..., pp. 201-202. 